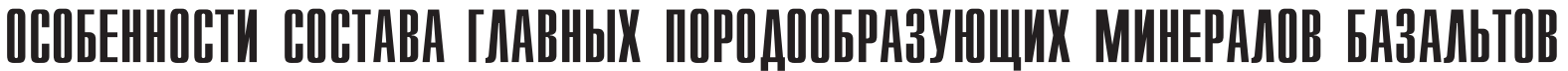

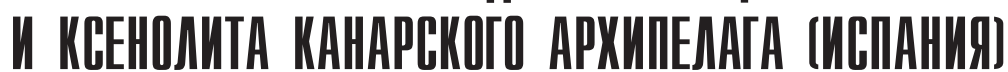

\author{
В. А Крылова, И. Ф. Гертнер \\ Национальный исследовательский Томский государственный университет, Томск \\ krylova.vera1994@yandex.ru; labspm@ggf.tsu.ru
}

Статья посвящена особенностям химического состава главных породообразующих минералов базальтов с острова ЛаПальма, ксенолита с острова Лансароте Канарского архипелага (Испания). Основной задачей исследования выступала диагностика минерального состава данных пород. Рассмотрены несколько версий природы перидотитовых ксенолитов, отражающих их мантийное или коровое происхождение. Приводится описание химического состава главных породообразующих минералов, на основе которого предполагается кумулятивный генезис этих образований в глубинных магматических камерах с возможным вовлечением ксеногенных кристаллов из материала литосферной мантии.

Ключевые слова: породообразующие минералы, химический состав, ксенолит, минеральный тип, базальты, перидотит.

\section{FEATURES OF THE COMPOSITION OF THE MAIN ROCK-FORMING MINERALS OF BASALIS AND XENOLITHS OF THE CANARY ARCHPELAGD (SPAIN)}

\author{
V. A. Krylova, I. F. Gertner \\ Tomsk National Research State University, Tomsk
}

The article is devoted to studying the chemical composition of the main rock-forming minerals of basalts from the island of La Palma, xenolith from the island of Lanzarote of the Canary Archipelago (Spain). The main task of the research is the diagnosis of mineral composition of these rocks. Peridodite xenoliths can be of several types reflecting their mantle or crust origin. The chemical composition of the main rock-forming minerals is described, which testifies to a cumulative genesis of these formations in deep magmatic chambers with possible inclusion of xenogenic crystals from lithospheric mantle material.

The main research methods were petrographic diagnostics and micro X-ray spectral analysis of the chemical composition of the main rock-forming minerals by Tescan Vega II LMU electron microscope equipped with INCA Energy 350 energy dispersive spectrometer (with Si ( $\mathrm{Li}$ ) Standart detector). We found that the olivines and pyroxenes of basalts were characterized by a typical composition of volcanic rocks, which had been formed in near-surface conditions or as a result of direct outpouring. Variations in the composition of plagioclase from labrador to oligoclase allowed classifying these formations as subalkaline bases characteristic of intraplate oceanic magmatism. The study of the petrostructure of peridotite xenolith and the composition of its constituent minerals revealed the peculiarities of their formation. There are several versions of the nature of peridotite xenoliths, reflecting their mantle or crustal origin. The obtained results suggested the cumulative genesis of these formations in deep magma chambers, with the possible involvement of xenogenic crystals from lithospheric mantle material. The magmatic nature of xenolith was supported by the presence of endiopside and plagioclase in the intergranular space of large olivine and orthopyroxene grains. The elements of intracrystalline deformations and their high magnesian composition, corresponding to restite hyperbasites of ophiolite association, can be used to explain the mantle nature of large crystals of olivine and orthopyroxene.

Key words: rock-forming minerals, chemical composition, xenolith, mineral type, basalts, peridotite.

\section{Введение}

Острова Канарского архипелага имеют вулканическое происхождение. Они сформировались на достаточно крупном симаунте в зоне трансформного разлома Атлантического срединно-океанического хребта. Слагающие их породы представлены преимущественно субщелочными базальтами K-Na-уклона, реже отмечаются трахиты и нефелинсодержащие базиты. По своим геохимическим параметрам они соответствуют продуктам E-MORB- или OIB-типа [4]. Особенностью текстуры данных вулканитов выступает частое присутствие ксеногенных включений перидотитового состава $[1,3]$ и осадочных пород $[5,12,13]$. Первые часто рассматриваются в качестве мантийных ксенолитов. На примере перидотитовых ксенолитов и базальтов остро- вов Гран-Канария, Тенерифе и Ла-Гомера предполагается активное взаимодействие материала ксенолитов с метасоматическими растворами корового и мантийного происхождения [2, 9]. В целом природа ксеногенных включений остается достаточно дискуссионной.

Для выявления условий формирования исследуемых пород был изучен состав главных породообразующих минералов базальтов и ксенолита. Изучение химического состава породообразующих минералов базировалось на результатах микрорентгеноспектрального анализа в ЦКП «Аналитический центр геохимии природных систем». Было изучено 3 образца горных пород и 79 определений химического состава минеральных фаз (оливина, пироксена, плагиоклаза, хромшпинелида, ильменита и карбонатов). В данной работе обсуж-

Для цитирования: Крылова В. А, Гертнер И. Ф. Особенности состава главных породообразующих минералов базальтов и ксенолита Канарского архипелага (Испания) // Вестник геонаук. 2020. 4(304). С. 3-8. DOI: 10.19110/geov.2020.4.1.

For citation: Krylova V. A., Gertner I. F. Features of the composition of the main rock-forming minerals of basalts and xenoliths of the Canary Archipelago (Spain). Vestnik of Geosciences, 2020, 4(304), pp. 3-8. DOI: 10.19110/geov.2020.4.1. 
даются особенности состава только основных породообразующих минералов.

\section{Краткая петрографическая характеристика изученных образцов}

По своим петрографическим особенностям изученные образцы отвечают основным типам пород, распространенных в вулканитах Канарского архипелага [6]. Образец А-1685 представлен порфировидным анамези- том (рис. 1, А, В). В качестве вкрапленников (1-3 мм) наблюдаются изоморфные кристаллы оливина и клинопироксена со слабой сиреневой окраской. Основная масса достаточно раскриталлизована (до 0.3 мм), имеет интергранулярную структуру, обусловленную более крупными лейстами плагиоклаза и интерстициальным агрегатом пироксена, оливина, плагиоклаза и рудного минерала. Присутствуют также менее раскристаллизованные разновидности с порфировыми выделениями плагиоклаза (обр. 3138).
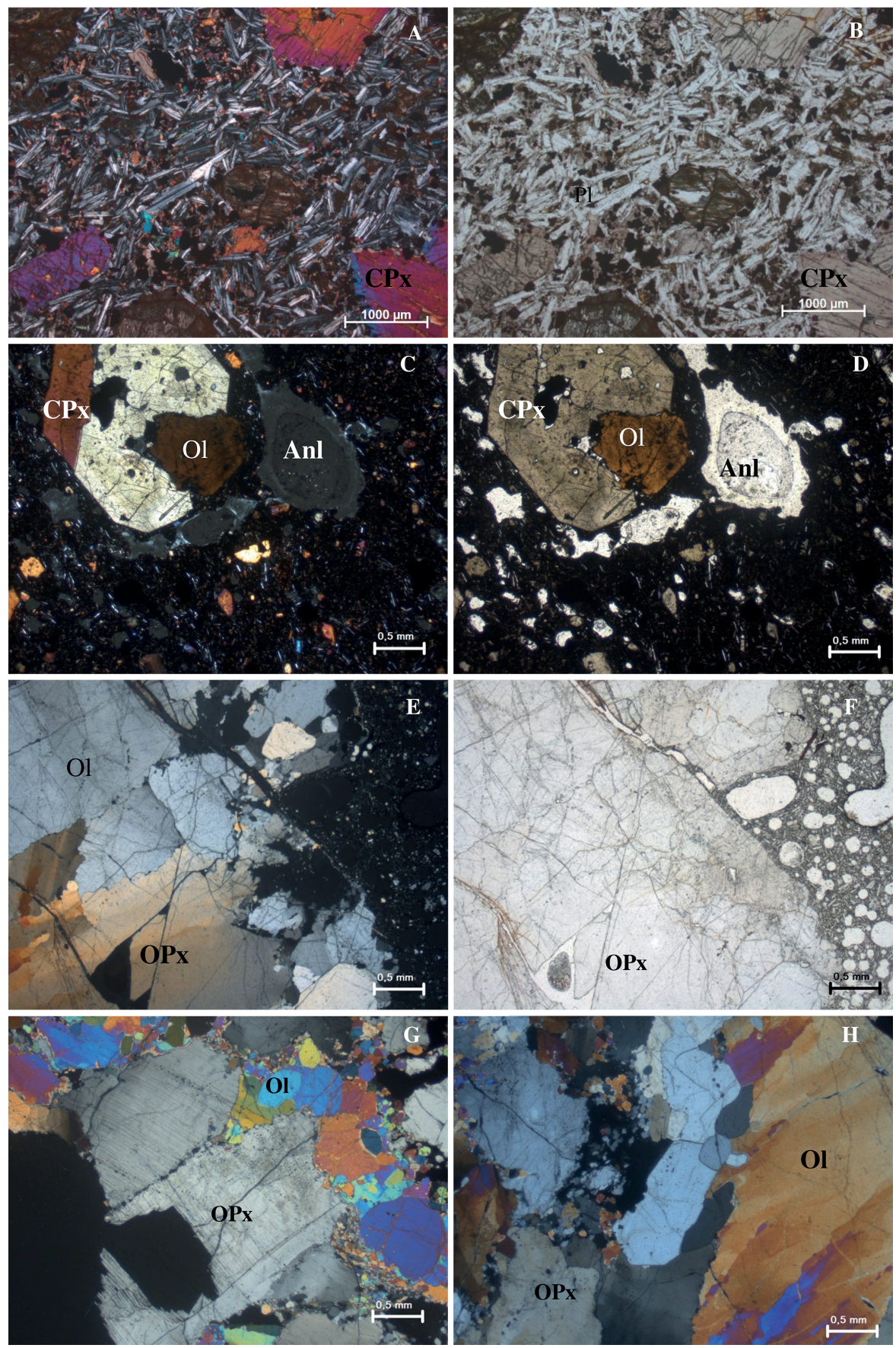

Рис. 1. Особенности микроструктуры базальтов и перидотитового ксенолита изученных образцов: А, В - порфировидный долерит, образец А-1685; C, D - пироксеновый амигдолоидный порфирит, образец А-1688; Е, F - контакт перидотитового ксенолита с вмещающим миндалекаменным базальтом, образец А-3; G, Н - протогранулярная с элементами порфирокластической структура перидотитового ксенолита, образец А-3 (слева на фото николи скрещены, справа николи параллельны). Условные обозначения: CPx - клинопироксен; Pl - плагиоклаз; Anl - анальцим; Ol - оливин; OPx - ортопироксен

Fig. 1. Petrofabric features of basalts and peridotite xenolith of studied samples. A, B - porphiric dolerite. A-1685; C, D - amigdaloid pyroxene porphirite, sample A-1688; E, F - boundary between peridotite xenolith and host basalt, sample A-3; G, H - protogranular with elements of porphiroclastic structures of peridotite xenolith, sample A-3 (on the left of the photo - crossed nicols, on the right parallel nicols). Symbols: $\mathrm{Cpx}$ - clinopyroxene, $\mathrm{Pl}$ - plagioclase, Anl — analcime, $\mathrm{Ol}$ - olivine, OPx - orthopyroxene 
Образец А-1688 интерпретируется как пироксеновый порфирит с обильными миндалинами анальцима (рис. 1, C, D), которые по размеру иногда сопоставимы с самими вкрапленниками (0.5 мм). Кроме клинопироксена присутствуют крупные (до 0.5 мм) чешуйки бурой слюды. Основная масса сложена лейстами плагиоклаза, мелкими зернами пироксена и рудного минерала. Отмечаются участки с пилотакситовой структурой.

Образец А-3 представлен перидотитовым ксенолитом в амигдалоидном базальте. Вмещающий вулканит слабо раскристаллизован и изобилует мелкими миндалинами анальцима, что позволяет сопоставлять его с предыдущей породой (рис. 1, F). Собственно ксенолит имеет резкие границы без признаков взаимодействия с вмещающим субстратом (рис. 1, E, F). Перидотит сложен крупными (до 3-4 мм) кристаллами оливина с характерными признаками внутрикристаллических деформаций (полосы излома или «кинк-банд» структуры) и ортопироксеном со следами распада «пижонитового» типа. Структура перидотита протогранулярная с элементами порфирокластовой (рис. 1, G, Н). Последняя особенность обусловлена присутствием внутри крупных кристаллов мелкозернистого (0.2-0.3 мм) интерстициального агрегата, сложенного плагиоклазом, клинопироксеном, оливином и рудным минералом. В составе крупнозернистой перидотитовой фракции постоянно присутствует также хромшпинелид с характерным вишневым оттенком в параллельных николях.

\section{Методика исследований}

Анализ вещественного состава породообразующих минералов, а также качественные изображения характера взаимоотношения минеральных ассоциаций и минеральных индивидов проводился методом рентгеноспектрального микроанализа в режиме обратнорассеянных электронов (режим BSE) на электронном сканирующем микроскопе Tescan Vega II LMU, оборудованном энергодисперсионным спектрометром INCA Energy 350 (с детектором $\mathrm{Si}(\mathrm{Li}) \mathrm{Standart})$. Ошибка определения концентраций главных оксидов составляла 0.05-0.1\%. Для исследований из отобранных образцов были выпилены плоскопараллельные аншлифы толщиной 3-4 мм. Перед проведением аналитических работ на поверх- ность изучаемых образцов предварительно напылялся слой углерода толщиной 25-30 нм.

\section{Результаты исследований}

Оливины в базальте (обр. А-1688) были изучены во вкрапленниках, в ксенолите (обр. А-3) - в крупных зернах, в ортопироксене - в более мелких идиоморфных включениях. Оливины представлены форстеритом и хризолитом. По содержанию фаялитового минала можно выделить две относительно контрастные группы. Первая группа фиксирует максимальные значения железистости (26.8-27.1 \% Fa), которые наблюдаются во вкрапленниках базальта. Ко второй группе отнесены форстериты и хризолиты (7.7-16.1 \% Fa), которые представлены в ксенолите перидотита. Присутствие оливина повышенной железистости (13-16\% Fa) свойственно магматическим оливинам, сформировавшимся в промежуточной глубинной камере на уровне нижней коры и представленным вкрапленниками из ультраосновных вулканитов $[10,14]$. Химический состав изученных оливинов показан в таблице 1.

Содержание $\mathrm{CaO}$ изменяется от 0.00 до 0.67 вес.\%. Здесь прослеживается четкая закономерность. Вкрапленники оливина в базальтах характеризуются резко повышенными концентрациями оксида кальция (0.40.7 вес. \%), тогда как в оливинах перидотитовых ксенолитов его роль крайне мала (не более 0.2 вес. \%). Содержание кальция в оливине является своеобразным геобарометром [11], разделяющим поля вулканических и плутонических ультрамафитов. На бинарной диаграмме « $\mathrm{CaO}-\mathrm{Fa}$ (рис. 2) основная масса фигуративных точек попадает в ограниченную область значений $0.0-0.2$ вес. \%, которые характерны для оливинов из пород ксенолитов, сформировавшихся на значительной глубине. Повышенные содержания $\mathrm{CaO}$ (0.43-0.67) фиксируются в оливинах из базальта, где получили развитие вкрапленники гипабиссальных фаций.

Пироксены по результатам исследования были определены и в ксенолите, и во вкрапленниках из базальтов. При этом были диагностированы как кальциево-магниевые (моноклинные), так и магнезиально-железистые (ромбические) разновидности (табл. 2). Ортопироксены наблюдаются исключительно в перидотите (обр. А-3).

Таблица № 1. Химический состав оливинов (мас. \%)

Table 1. The chemical composition of olivines (wt. \%)

\begin{tabular}{|c|c|c|c|c|c|c|c|}
\hline \multirow{2}{*}{$\begin{array}{c}\text { Окислы } \\
\text { Oxides }\end{array}$} & A-3/1 & $\mathrm{A}-3 / 2$ & A-3/3 & $\mathrm{A}-3 / 4$ & A-1688/6 & A-1688/7 & A- $1688 / 8$ \\
\hline & 1 & 2 & 3 & 4 & 5 & 6 & 7 \\
\hline $\mathrm{SiO}_{2}$ & 42.31 & 41.77 & 41.83 & 41.27 & 39.63 & 39.42 & 39.55 \\
\hline $\mathrm{TiO}_{2}$ & - & - & - & - & 0.37 & - & - \\
\hline $\mathrm{FeO}$ & 7.66 & 12.44 & 10.75 & 15.04 & 23.32 & 23.36 & 23.45 \\
\hline $\mathrm{MnO}$ & - & - & - & 0.23 & 0.52 & 0.64 & 0.52 \\
\hline $\mathrm{MgO}$ & 49.50 & 45.22 & 46.94 & 43.19 & 35.20 & 35.98 & 35.87 \\
\hline $\mathrm{CaO}$ & 0.20 & 0.20 & 0.18 & - & 0.94 & 0.60 & 0.61 \\
\hline $\mathrm{NiO}$ & 0.34 & 0.37 & 0.30 & 0.27 & - & - & - \\
\hline Сумма / Sum & 100.01 & 100 & 100 & 100 & 99.98 & 100 & 100 \\
\hline
\end{tabular}

Расчёт формул оливинов производился на 4 иона (O) / Olivine formulas are calculated for 4 ions (O)

$\left(\mathrm{Mg}_{1.79}, \mathrm{Fe}_{0.15}\right) \mathrm{Ni}_{0.01}\left[\mathrm{Si}_{1.02} \mathrm{O}_{4}\right] ;\left(\mathrm{Mg}_{1.67}, \mathrm{Fe}_{0.26}\right) \mathrm{Ca}_{0.01} \mathrm{Ni}_{0.01}\left[\mathrm{Si}_{1.03} \mathrm{O}_{4}\right] ;\left(\mathrm{Mg}_{1.72}, \mathrm{Fe}_{0.22}\right) \mathrm{Ni}_{0.01}\left[\mathrm{Si}_{1.03} \mathrm{O}_{4}\right]$;

$\left(\mathrm{Mg}_{1.61}, \mathrm{Fe}_{0.31}\right) \mathrm{Ni}_{0.01}\left[\mathrm{Si}_{1.03} \mathrm{O}_{4}\right] ;\left(\mathrm{Mg}_{1.37}, \mathrm{Fe}_{0.51}\right) \mathrm{Ca}_{0.03} \mathrm{Ti}_{0.01} \mathrm{Mn}_{0.01}\left[\mathrm{Si}_{1.03} \mathrm{O}_{4}\right] ;\left(\mathrm{Mg}_{1.40}, \mathrm{Fe}_{0.51}\right) \mathrm{Ca}_{0.02} \mathrm{Mn}_{0.01}\left[\mathrm{Si}_{1.03} \mathrm{O}_{4}\right]$;

$\left(\mathrm{Mg}_{1.39}, \mathrm{Fe}_{0.51}\right) \mathrm{Ca}_{0.02} \mathrm{Mn}_{0.01}\left[\mathrm{Si}_{1.03} \mathrm{O}_{4}\right]$ 


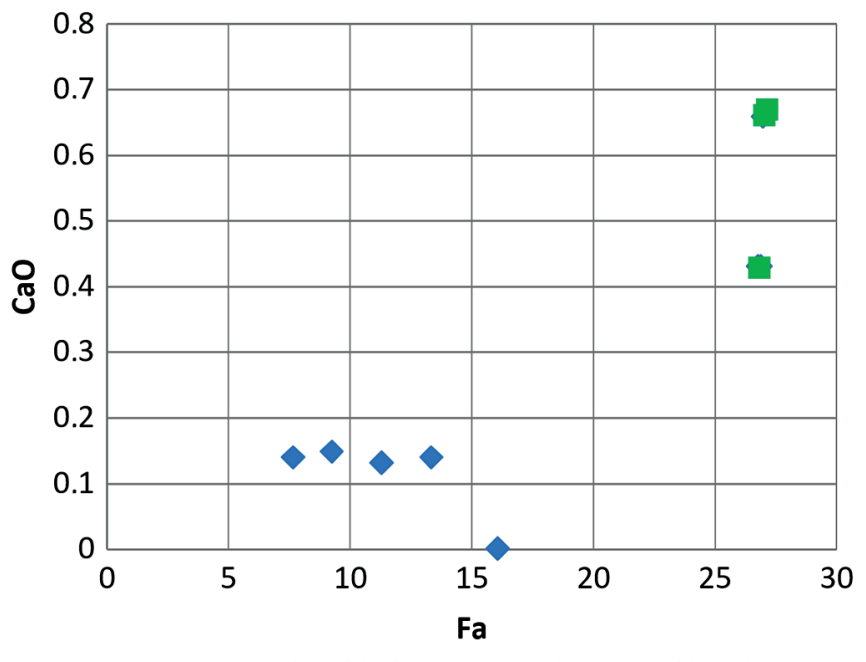

перидотиты / peridotites — базальты / basalts

Рис. 2. Вариации содержания $\mathrm{CaO}$ в оливинах

Fig. 2. Variations in $\mathrm{CaO}$ content in olivines

Они довольно однородны по составу и отвечают энстатиту, что позволяет сопоставлять данные образования с продуктами реститовой мантии. Вместе с тем в данных породах обнаружены и кальциевые разновидности этого минерала, которые представлены в порфирокластовом агрегате. Клинопироксены обнаружены в перидотите (обр. А-3) и в базальтах (обр. А-1685, А-1688), (рис. 3). Для вкрапленников в базальтах характерны более кальциевые и более железистые разновидности типа диопсида и авгита. В составе перидотитовых ксенолитов установлены преимущественно эндиопсиды.

Плагиоклазы представлены в большом количестве в базальтах (обр. А-1685, 1688) и в ксенолите (обр. А-3). Чтобы определить состав плагиоклаза, мы провели сле- дующие расчёты по формуле: $\mathrm{Ca} /(\mathrm{Ca}+\mathrm{Na}+\mathrm{K})=$ № плагиоклаза. В результате были определены плагиоклазы, по составу соответствующие лабрадору, битовниту, андезину и олигоклазу с повышенным содержанием ортоклазового минала (табл. 3, рис. 4). Для перидотитовых ксенолитов характерны лабрадоры, а для собственно базальтов - более широкий спектр: от битовнита до обогащенного калием олигоклаза. Наличие основного

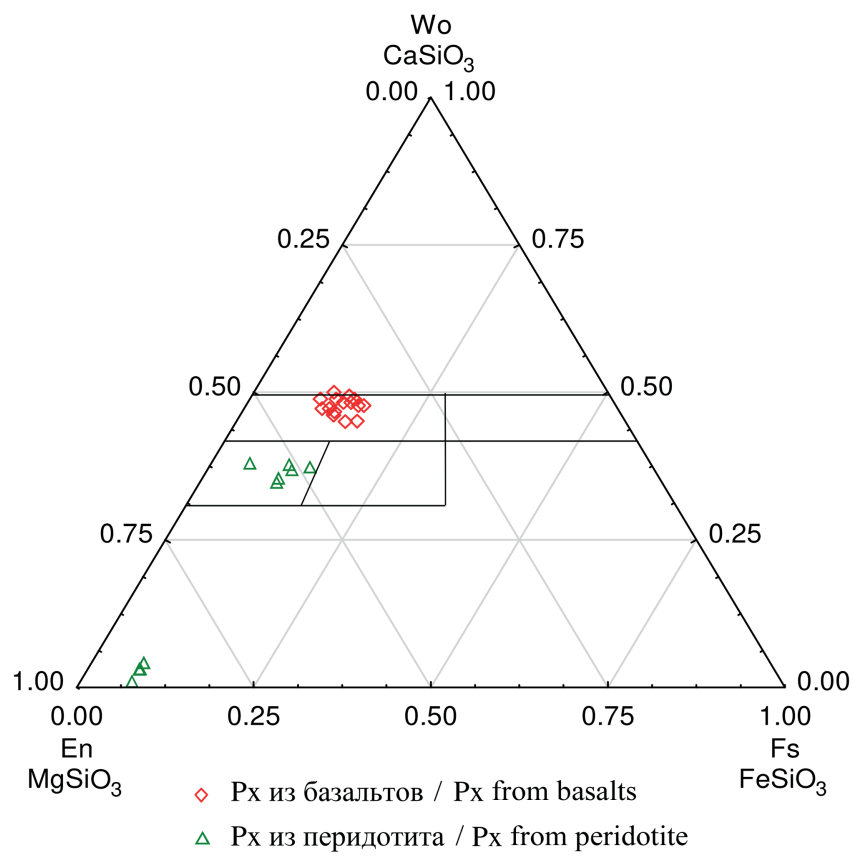

Рис. 3. Состав пироксенов из базальтов и перидотита Канарских островов

Fig. 3. Composition of pyroxenes from basalts and peridotite of the Canary Islands

Таблица 2. Представительный химический состав пироксенов (мас. \%)

Table 2. The chemical composition of pyroxenes (wt. \%)

\begin{tabular}{|c|c|c|c|c|c|c|c|}
\hline Окислы & A-1685/9 & A-1685/10 & A-3/11 & $A-3 / 12$ & $A-3 / 13$ & A-1688/14 & A-1688/15 \\
\hline Oxides & 1 & 2 & 3 & 4 & 5 & 6 & 7 \\
\hline $\mathrm{SiO}_{2}$ & 50.61 & 48.86 & 55.94 & 51.45 & 58.29 & 47.94 & 50.93 \\
\hline $\mathrm{TiO}_{2}$ & 2.45 & 3.53 & - & 1.94 & - & 3.49 & 1.95 \\
\hline $\mathrm{Al}_{2} \mathrm{O}_{3}$ & 3.82 & 5.26 & 1.67 & 4.14 & 1.32 & 5.78 & 4.30 \\
\hline $\mathrm{Cr}_{2} \mathrm{O}_{3}$ & - & - & 1.10 & 0.37 & 0.68 & - & 0.30 \\
\hline $\mathrm{FeO}$ & 9.74 & 9.15 & 3.10 & 8.53 & 4.64 & 7.65 & 6.10 \\
\hline $\mathrm{MnO}$ & 0.24 & - & - & - & - & 0.22 & 0.20 \\
\hline $\mathrm{MgO}$ & 11.38 & 11.45 & 19.59 & 16.13 & 33.44 & 13.16 & 13.52 \\
\hline $\mathrm{CaO}$ & 21.23 & 21.15 & 18.20 & 17.15 & 1.63 & 21.31 & 22.00 \\
\hline $\mathrm{Na}_{2} \mathrm{O}$ & 0.53 & 0.60 & 0.40 & 0.28 & - & 0.46 & 0.70 \\
\hline Сумма / Sum & 100 & 100 & 100 & 99.99 & 100 & 100.01 & 100 \\
\hline Wo & 47.8 & 47.73 & 38.04 & 37.36 & 3.16 & 46.74 & 18.89 \\
\hline En & 35.5 & 36.36 & 56.52 & 48.35 & 89.47 & 40.22 & 41.11 \\
\hline Fs & 16.7 & 15.9 & 5.43 & 14.28 & 7.37 & 13.04 & 10 \\
\hline f, $\%$ & 31.9 & 30.4 & 8.7 & 22.8 & 7.6 & 24.4 & 19.5 \\
\hline
\end{tabular}

Расчёт формул пироксенов производился на 3 иона $(\mathrm{O})$ / Pyroxene formulas are calculated for 3 ions $(\mathrm{O})$

$\mathrm{Ca}_{0.43} \mathrm{Mg}_{0.32} \mathrm{Fe}_{0.15} \mathrm{Na}_{0.02} \mathrm{Al}_{0.08} \mathrm{Ti}_{0.03}\left[\mathrm{Si}_{0.95} \mathrm{O}_{3}\right] ; \mathrm{Ca}_{0.42} \mathrm{Mg}_{0.32} \mathrm{Fe}_{0.14} \mathrm{Na}_{0.02} \mathrm{Al}_{0.12} \mathrm{Ti}_{0.05}\left[\mathrm{Si}_{0.91} \mathrm{O}_{3}\right]$;

$\mathrm{Ca}_{0.35}\left(\mathrm{Mg}_{0.52} \cdot \mathrm{Fe}_{0.05} \cdot \mathrm{Al}_{0.04}\right) \mathrm{Na}_{0.01} \mathrm{Cr}_{0.02}\left[\mathrm{Si}_{1.00} \mathrm{O}_{3}\right] ; \mathrm{Ca}_{0.34}\left(\mathrm{Mg}_{0.44} \cdot \mathrm{Fe}_{0.13} \cdot \mathrm{Al}_{0.09}\right) \mathrm{Na}_{0.01} \mathrm{Ti}_{0.03} \mathrm{Cr}_{0.01}\left[\mathrm{Si}_{0.94} \mathrm{O}_{3}\right]$;

$\mathrm{Ca}_{0.03}\left(\mathrm{Mg}_{0.85} . \mathrm{Fe}_{0.07} \cdot \mathrm{Al}_{0.03}\right) \mathrm{Cr}_{0.01}\left[\mathrm{Si}_{1} \mathrm{O}_{3}\right] ; \mathrm{Ca}_{0.43} \mathrm{Mg}_{0.37} \mathrm{Fe}_{0.12} \mathrm{Na}_{0.02} \mathrm{Al}_{0.13} \mathrm{Ti}_{0.05}\left[\mathrm{Si}_{0.89} \mathrm{O}_{3}\right]$;

$\mathrm{Ca}_{0.44} \mathrm{Mg}_{0.37} \mathrm{Fe}_{0.09} \mathrm{Na}_{0.02} \mathrm{Al}_{0.09} \mathrm{Ti}_{0.03}\left[\mathrm{Si}_{0.94} \mathrm{O}_{3}\right]$ 
Таблица 3. Химический состав плагиоклазов (мас.\%)

Table 3. The chemical composition of plagioclases (wt. \%)

\begin{tabular}{|c|c|c|c|c|c|c|}
\hline \multirow[t]{2}{*}{$\begin{array}{c}\text { Окислы } \\
\text { Oxides }\end{array}$} & $\begin{array}{c}\text { A-1685/16 } \\
\text { Лабрадор } \\
\text { Labradorite }\end{array}$ & $\begin{array}{c}\text { A-1685/18 } \\
\text { Андезин } \\
\text { Andesine }\end{array}$ & $\begin{array}{c}\text { A-1688/19 } \\
\text { Лабрадор } \\
\text { Labradorite }\end{array}$ & $\begin{array}{l}\text { A-1688/20 } \\
\text { Битовнит } \\
\text { Bytownite }\end{array}$ & $\begin{array}{c}\text { А-3/21 } \\
\text { Лабрадор } \\
\text { Labradorite }\end{array}$ & $\begin{array}{c}\text { А-3/22 } \\
\text { Лабрадор } \\
\text { Labradorite }\end{array}$ \\
\hline & 1 & 2 & 3 & 4 & 5 & 6 \\
\hline $\mathrm{SiO}_{2}$ & 59.79 & 57.73 & 55.07 & 55.70 & 56.03 & 56.33 \\
\hline $\mathrm{Al}_{2} \mathrm{O}_{3}$ & 25.21 & 26.56 & 28.11 & 25.17 & 26.98 & 27.16 \\
\hline $\mathrm{FeO}$ & 0.41 & 0.38 & 0.72 & 2.92 & 1.24 & 0.82 \\
\hline $\mathrm{MgO}$ & & & & 0.41 & - & - \\
\hline $\mathrm{CaO}$ & 7.68 & 9.33 & 11.29 & 7.27 & 11.10 & 10.70 \\
\hline $\mathrm{Na}_{2} \mathrm{O}$ & 6.40 & 5.46 & 4.35 & 5.50 & 4.48 & 4.85 \\
\hline $\mathrm{K}_{2} \mathrm{O}$ & 0.51 & 0.54 & 0.47 & 3.02 & 0.16 & 0.14 \\
\hline Сумма / Sum & 100 & 100 & 100.01 & 99.99 & 99.99 & 100 \\
\hline
\end{tabular}

Расчёт формул плагиоклазов производился на 24 иона (O) / Plagioclase formulas are calculated for 24 ions (O)

$\mathrm{Na}_{2.7} \mathrm{Ca}_{1.77} \mathrm{~K}_{0.15} \mathrm{Fe}_{0.09}\left[\mathrm{Al}_{6.36} \mathrm{Si}_{12.8} \mathrm{O}_{24}\right] ; \mathrm{Na}_{2.27} \mathrm{Ca}_{2.16} \mathrm{~K}_{0.15} \mathrm{Fe}_{0.07}\left[\mathrm{Al}_{6.74} \mathrm{Si}_{12.44} \mathrm{O}_{24}\right]$;

$\mathrm{Ca}_{2.63} \mathrm{Na}_{1.83} \mathrm{~K}_{0.13} \mathrm{Fe}_{0.13}\left[\mathrm{Al}_{7.19} \mathrm{Si}_{11.94} \mathrm{O}_{24}\right] ; \mathrm{Na}_{2.35} \mathrm{Ca}_{1.71} \mathrm{~K}_{0.84} \mathrm{Mg}_{0.14} \mathrm{Fe}_{0.54}\left[\mathrm{Al}_{6.54} \mathrm{Si}_{12.28} \mathrm{O}_{24}\right]$;

$\mathrm{Ca}_{2.58} \mathrm{Na}_{1.89} \mathrm{~K}_{0.05} \mathrm{Fe}_{0.22}\left[\mathrm{Al}_{7.22} \mathrm{Si}_{12.14} \mathrm{O}_{24}\right] ; \mathrm{Ca}_{2.48} \mathrm{Na}_{2.03} \mathrm{~K}_{0.03} \mathrm{Fe}_{0.14}\left[\mathrm{Al}_{6.93} \mathrm{Si}_{12.18} \mathrm{O}_{24}\right]$

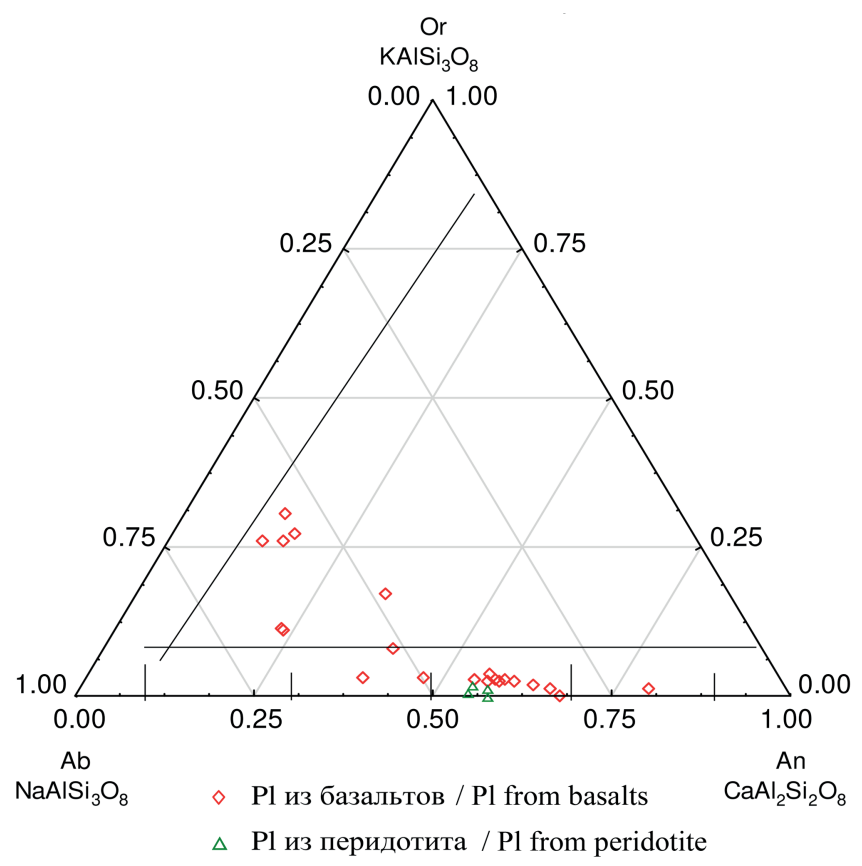

Рис. 4. Состав плагиоклазов из базальтов и перидотита Канарских островов

Fig. 4. Composition of plagioclases from basalts and peridotite of the Canary Islands

плагиоклаза в составе «ксеногенных» перидотитов явно указывает на их кумулятивную природу. С другой стороны, присутствие достаточно кислых разновидностей плагиоклаза в составе базальтов и обогащение их калием позволяет подтвердить повышенную щелочность исходного магматического расплава. В перидотитовых ксенолитах плагиоклаз диагностирован только в межгранулярном (порфирокластовом) агрегате.

Хромшпинелиды в ксенолитах по своему химическому составу соответствуют алюмохромитам.

\section{Заключение}

На основе анализа породообразующих минералов базальтов и ксенолитов ультрамафитов, содержащихся в вулканических породах островов Ла-Пальма и
Лансароте, можно сделать вывод, что собственно вулканиты представлены субщелочными разновидностями базитов типа OIB, а ксенолиты, вероятно, являются фрагментами кумулятивных образований из глубинной камеры на границе литосферной мантии и океанической коры [7]. Подтверждением этого выступают особенности минерального парагенезиса данных ассоциаций. Присутствие достаточно кислых плагиоклазов с повышенным содержанием минала ортоклаза позволяют однозначно идентифицировать их с такими разновидностями, как гавайиты и муджеириты, которые характерны для океанических островов внутриплитного происхождения. Для ксенолитов острова Лансароте присутствие высокожелезистого оливина (до 13-16 \% Fa-минала), эндиопсида и основного плагиоклаза также подтверждает их образование исключительно в глубинной камере и не допускает природу мантийных ксенолитов ниже астеносферного слоя или собственно литосферной мантии. Дополнительным критерием в пользу данной точки зрения о кумулятивном происхождении данных ультрамафитов выступают исследования по петроструктурному анализу ориентировок зерен оливина. Проведенные методом EBSD (детектор обратноотраженных электронов) петроструктурные исследования крупных зерен оливина в ксенолитах указывают на их формирование в условиях отложения ранних кумулатов. Петроструктурные узоры данного минерала более сопоставимы с оливинами дунитов из Йоко-Довыренского плутона и заметно отличаются от ориентировок альпинотипных (реститовых) гипербазитов северного склона Кузнецкого Алатау [8].

Вместе с тем нельзя игнорировать ряд признаков (внутрикристаллические деформации крупных зерен оливина, его магнезиальный состав и присутствие энстатита), которые поддерживают точку зрения о мантийной природе ксенолитов острова Лансароте. Возможно, ряд кристаллов имеют ксеногенное происхождение, как, например, в породах марианит-бонинитовой серии. Для решения данной проблемы необходимы более детальные геохимические исследования на уровне как валовых составов пород, так и самих породообразующих минералов. Многие аспекты могут 
быть решены при анализе изотопов $\mathrm{Nd}, \mathrm{Sr}, \mathrm{O}$ и других элементов.

Исследования выполнены при поддержке Министерства науки и высшего образования Российской Федерации в рамках выполнения государственного задания (проект № 0721-2020-0041).

Автор выражает благодарность профессору Университета Саламанки Гутиеррез-Алонсо Габриэлю за предоставление образцов и помощь в интерпретации.

\section{Литература / References}

1. Amundsen H. E. F. (1987). Peridotite xenoliths from Gran Canaria, Canary islands; evidence for menasomatic processes and partial melting in the lower oceanic crust. Neues Jahburg. Miner. Abh, Vol. 156, No. 2, pp. 121-140.

2. Frezzotti M. L., Touret J. L. R. et al. (11994). Melt and fluid inclusionsin dunite xenolithsfrom La Gomera,Canary islands: tracking the mantle metasomatic fluids. Eur. J. Mineral, Vol. 6, pp. 805-817.

3. Grachev A. F. (2012). MORB-like mantle beneath Lansorote island, Canary islands. Russian journal Earth sciences. Vol. 12, ES3004.

4. Hoernle K. (1998) Geochemistry of Jurassic oceanic crust beneath Gran Canaria (Canary islands): implicationrustal recycling and assimilation. Journal of Petrology. Vol. 39, No. 5, pp. 859-880.

5. Jagerup B. (2016). Ursprunget tillGrant Canarias xenoliter // .org/Villavagen 16.752 /www.diva-portal

6. Krylova V. A., Gertner I. F. Sedimentary deposits and petrography of the basalts of the island of Tenerife of the Canary archipelago (Spain). IOP Conference Series: Earth and Environmental Science, 2017, Vol. 110, pp. 1-7.
7. Krylova V. A., Gertner I. F. Gutierrez-Alonso G. Origin of ultramafic xenoliths from Canary Islands //Large Igneous Provinces through earth history: mantle plumes, supercontinents, climate change, metallogeny and oil-gas, planetary analogues (LIP-2019). Abstract volume of the 7 International Conference. Tomsk: CSTI Publishing house, 2019, pp. 70-71.

8. Krylova V. A., Gertner I. F. Petro fabric characteristics of olivine from xenoliths, peridotites, and basalts (from Canary Islands, Kuznetsk Alatau and Yoko-Dovyren Massif). IOP Conference Series: Earth and Environmental Science, 2019, Vol. 319, pp. 1-7.

9. Neumann E. R. (2002). Nantle xenoliths from Tenerife (Canary islands): evidence for reactions betweenmqntle peridotites and siliccarbonatite melts including Ca metasomatism. Journal of Petrology, Vol. 43, No. 5, pp. 825-857.

10. Rudnick R. L. Xenoliths - samples of the lower continental crust. In: Fountain D. M., Arculus R. J. Kay R. W. (Eds.), The Continental Lower Crust, Elsevier, Amsterdam, 1992, pp. 269-316.

11. Simkin T., Smith G. Minor element distribution of olivine. J. Geol. 1970, V. 78, No 3, pp. 304-325

12. Traver C. M. (2013). A petrological and geochemical study of mantle and crustal xenoliths from Lanszarote, Canary islands. UC San Diego electronic theses and dissertation. https://scholarship.org/item/02f8g0k.

13. Troll V. R., Rluger A. et al. (2012). Floating stoneds off El Hierro, Canaryislands: xenoliths pre-islsnd sedimentary origin in theearly products of the october 2011 eruption. Solid Earth. No. 3, pp. 97-110.

14. Volkova N., Egorova V., Izokh A., Shelepaev R. The lithosphere beneath Sangilen Plateau, Siberia: evidence from peridotite and pyroxenite xenoliths from alkaline basalts. 32nd International Geological Congress, Florence, Italy, Abstracts Volume, 2004, pp. 1154

Поступила в редакцию / Received 16.03.2020 